\title{
JOMSTI
}

JDURNAL DF MUSIL

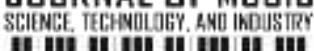

Journal of Music Science, Technology, and Industry

E-ISSN 2622-8211

Vol. 3 No. 1 (2020): 91-102

\section{Peran Musik dalam Film Score}

\author{
Dimas Phetorant \\ Program Studi Musik, Fakultas Seni Pertunjukan, Institut Kesenian Jakarta \\ email: dimasphetorant@mail.ru
}

\begin{abstract}
Scores are things that cannot be separated from the film. The score has an important role in the film. Apart from being a communication tool, scores are needed to convey visual messages. The rise of filmmaking lately especially those related to scores requires composers with a variety different disciplines. This paper discusses the score on the film. The method used is observation. The data studied is in the form of journals, books, pictures, videos, which have been described in written form.
\end{abstract}

Keywords: score, music, psychology, film.

\begin{abstract}
ABSTRAK
Score merupakan hal yang tidak bisa dilepaskankan dari film score mempunyai peranan penting pada film. Selain sebagai alat komunikasi, score dibutuhkan untuk menyampaikan pesan visual. Maraknya pembuatan film belakangan ini terutama yang berhubungan dengan score, memerlukan komponis dengan berbagai disiplin ilmu yang berbeda. Tulisan ini membahas tentang score pada film. Metode yang digunakan adalah observasi. Data yang dikaji adalah berupa jurnal, buku, gambar, video, yang sudah dideskripsikan ke dalam bentuk tulisan.

Kata kunci: score, musik, psikologi, film.
\end{abstract}

\section{PENDAHULUAN}

Sejak abad ke-20, musik telah berkembang sedemikian pesat di berbagai ranah. Musik menurut Phetorant (2018: 4) adalah gabungan atau kumpulan frekuensi yang dapat di dengar. Mengacu pada definisi tersebut di atas, ruang lingkup musik sangat luas. Fungsi musik pun juga sangat beragam dalam kehidupan. Sebagai hiburan, musik seni, ekonomi, industri (baik itu pariwisata, periklanan, televisi), pendidikan, musik film dan yang lainnya. Musik menjadi bagian utama/ pendukung utama dalam melengkapi dan menyempurnakan beragam bentuk kesenian dan budaya, salah satunya film.

Film merupakan gambar hidup atau gambar yang bergerak. Undang-Undang (UU) Republik Indonesia No. 8 tahun 1992 pasal 1 mendefinisikan film adalah karya 
cipta seni dan budaya yang merupakan media komunikasi massa pandang-dengar yang dibuat berdasarkan asas sinematografi dengan direkam pada pita seluloid, pita video, piringan video, dan/atau bahan hasil penemuan teknologi lainnya dalam segala bentuk, jenis, dan ukuran melalui proses kimiawi, proses elektronik, atau proses lainnya, dengan atau tanpa suara, yang dapat dipertunjukkan dan/atau ditayangkan dengan sistem proyeksi mekanik, elektronik, dan/atau lainnya.

Definisi lain menurut pasal 1 ayat (1) Undang-Undang Republik Indonesia Nomor 33 Tahun 2009 Tentang Perfilman (UU baru tentang perfilman) film adalah karya seni budaya yang merupakan pranata sosial dan media komunikasi massa yang dibuat berdasarkan kaidah sinematografi dengan atau tanpa suara dan dapat dipertunjukkan.

Musik pada film merupakan satu kesatuan media yang kuat. Pesan yang ingin disampaikan lebih mudah di terima oleh masyarakat (penonton) dengan menggunakan kedua media tersebut. Keindahan film di tangkap oleh indra visual, sedangkan keindahan musik lewat indra auditoris. Musik pada film sering juga di sebut dengan film scoring atau musik film.

Musik film selain sebagai ilustrasi sebuah adegan, juga tanpa disadari bisa memanipulasi emosi penonton. Interaksi antara pengalaman visual dan auditoris sangat menarik. Cara paling sederhana dan langsung dalam membuat pernyataan adalah lewat musik. Audiens secara sadar atau tidak ketika memperhatikan peristiwa yang terjadi di layar, mereka juga mendengarkan scoring-nya (score). Seringkali efek dramatisasi juga dapat meningkat dengan musik. Tidak hanya itu, wajah, suara, efek suara juga dapat berubah.

Musik film (film scoring) sedikit berbeda dengan musik pada umunya. Score dapat diartikan sebagai musik penunjang yang melatar belakangi sebuah film. Menurut London (1970: 158), score berfungsi menekankan, menggarisbawahi, menghubungkan, menafsirkan gerakan dan menjadi bagian dari pola dramatis sebuah visual dalam film. Seorang komponis film harus dapat menerjemahkan frekuensi visual ke dalam scorenya. Untuk itu, beberapa unsur psikologi menjadi penting bagi seorang komponis. Psikologi merupakan suatu displin ilmu yang mempelajari tentang jiwa. Komponis harus dapat meleburkan unsur musik dan gambar menjadi sebuah kesatuan. 
Selain score, salah dua hal lain musik pada film adalah soundtrack dan sound effect-nya. Soundtrack dapat diartikan sebagai lagu tema sebuah lagu, dapat disenandungkan. Lagu yang di buat secara khusus, dan sesuai dengan kisah film yang bersangkutan. Bisa lagu pop, jazz, klasik, rock dan lainnya. Biasanya di putar pada pertengahan dan kredit penutup film, tetapi tidak menutup kemungkinan di putar akhir dan awal film. Contoh yang sangat populer adalah soundtrack film Titanic: My Heart Will Go On yang dinyanyikan oleh Celline Dion.

Sedangkan sound effect adalah suara tambahan untuk mendukung score. Jenisnya banyak, bisa dari suara alam, suara dalam kehidupan sehari-hari, suara yang sering tidak kita sadari, suara dari alat musik, sampai suara buatan menggunakan software. Seperti suara pintu, suara knalpot, suara angin, suara gemericik air dan sebagainya. Sound effect, soundtrack, dan score dapat membawa imajinasi terdalam seseorang dalam menonton sebuah film.

Pembuatan score melibatkan banyak orang dengan disiplin ilmu yang berbeda. Berbagai ragam musik, instrumen dan sound effect dapat digunakan untuk mendukung sebuah film. Komponis dan sutradara memegang peranan penting. Dalam prosesnya, akan timbul banyak permasalahan. Banyak pembuat film tidak memiliki pengetahuan tentang musik, begitu pula sebaliknya. Pembuat film dan komponis harus saling menghormati disiplin ilmunya masing-masing.

Film memerlukan musik untuk membantu gerakan yang terlihat secara visual. Score dapat menutup beberapa kekurangan dari frekuensi visual. Jika dipergunakan secara tepat, score adalah media yang kuat untuk memunculkan rasa emosi penonton.

Musik score harus bisa membantu penonton membangun suasana sesuai dengan keperluan film tersebut. Score akan menonjolkan sebuah adegan, menegaskan suasana suatu tempat atau zaman, menggaris-bawahi dan mengomentari situasi kemanusiaan yang mungkin ditekankan pada saat situasi dramatis tertentu (Manvell, 1985: 116). Selain itu, score atau film tidak hanya digunakan sebagai hiburan. Score dapat digunakan sebagai media pendidikan, informasi dan media pengetahuan lainnya.

Berdasarkan latar belakang yang telah diuraikan di atas, penulis akan mendeskripsikan bagaimana proses score pada film, apa unsur yang harus diketahui, baik itu musik atau psikologi, dan sejarahnya. 


\section{METODE PENELITIAN}

Metode yang digunakan dalam penulisan ini adalah observasi dan kajian pustaka. Observasi yang dilakukan penulis dengan menonton beberapa film, khususnya yang berhubungan dengan musik. Hal ini dilakukan penulis agar mendapatkan gambaran tentang beragam jenis musik score. Selain itu, juga untuk mendapatkan informasi tentang proses dan ide pembuatan score. Selain observasi, penulis mengumpulkan data dengan menelaah berbagai sumber pustaka. Baik itu berupa buku, jurnal, dan yang lainnya.

Pendekatan yang digunakan pada penerjemahan ini adalah pendekatan kualitatif bersifat deskriptif analitik terhadap data yang dipaparkan dalam bentuk kata-kata atau gambar daripada angka-angka.

\section{PEMBAHASAN}

Awalnya, sebelum menjadi bentuk seperti sekarang, film yang kita kenal adalah berupa film bisu. Film yang di buat lewat gerak, tanpa suara dan tanpa dialog. Juga, tak lupa Eksperimen dari Lumière bersaudara yang mempatenkan dan menemukan sinematograf. Awal penemuannya, peralatan sinematograf tersebut telah digunakan untuk merekam adegan-adegan yang singkat. Saat itu, musik dipikirkan sebagai sesuatu untuk menutupi kebisingan dari proyektor.

Mendengar film bisu, keheningan merupakan hal yang yang kurang lazim. Kecuali dalam sebuah tempat khusus, yaitu ruang hampa. Indra pendengaran kita masih bisa menangkap beberapa frekuensi, walaupun sangat terbatas. Normalnya, telinga yang sehat biasanya mendeteksi frekuensi pada jangkauan $16 \mathrm{~Hz}$ hingga 20000 Hz. ${ }^{1}$ Mendengar adalah seni menemukan keheningan. Dalam film bisu, hening merupakan scorenya.

Score merupakan jiwa film. Sebuah musik orisinal yang khusus dibuat sebagai musik latar untuk mengiringi sebuah film dari awal hinga akhir. Score dapat membuat suatu adegan menjadi lebih seru. Pada beberapa bagian tertentu, sebuah gambar belum dapat menyampaikan sebuah pesan, atau makna apa yang ingin pembuat film sampaikan. Untuk itu, score dapat membantu apa yang tidak dapat disampaikan oleh gambar.

\footnotetext{
${ }^{1}$ Herzt adalah satuan ukur frekuensi.
} 
Komponis film adalah seorang pendongeng. Komponis harus memiliki kemampuan untuk membentuk, mengubah, berkomunikasi atau bahkan mengejawantahkan keinginan pembuat film. Salah satu bekal utama yang harus dimiliki oleh komponis dalam pembuatan film adalah pengetahuan tentang timbre.

Timbre adalah karakteristik suara yang membedakan suara yang satu dengan yang lainnya. Komponis harus mempunyai wawasan yang luas tentang bunyi. Baik itu bunyi instrument (alat musik), bunyi alam dan yang lain. Timbre dipengaruhi oleh banyak hal, cara memainkan alat musik, perbedaan materi pembuat instrument, perbedaan suhu, dan juga perbedaan alat resonansi maupun eksperimen terhadap suatu alat.

Sebagai contohnya adalah film Psycho, sebuah film bergenre horor. Film yang di buat oleh Alfred Hitchcock tahun 1960 ini merupakan salah satu karya terbaiknya. Score pada film ini sangat kuat, menimbulkan dampak psikologis, terutama pada plot di kamar mandi. Scorenya menambah efek mencekam, menakutkan, dan mengerikan. Tanpa musik score, film tersebut hanya merupakan sebuah gambar hitam putih yang bergerak, tidak menakutkan. Tonton saja filmnya dengan, atau tanpa suara. Rasakan perbedaannya. Komponis filmnya adalah Bernard Herrmann. Tema score film tersebut selalu muncul ketika 'pelaku' melakukan aksinya. Timbre tinggi dan melengking yang sangat khas tersebut, di buat menggunakan string (biola), dengan pemilihan nada yang spesifik. Cara memainkannya dengan menggesek string pada ujung bridge, untuk mendapatkan efek ketegangan. Perhatikan gambar 1.

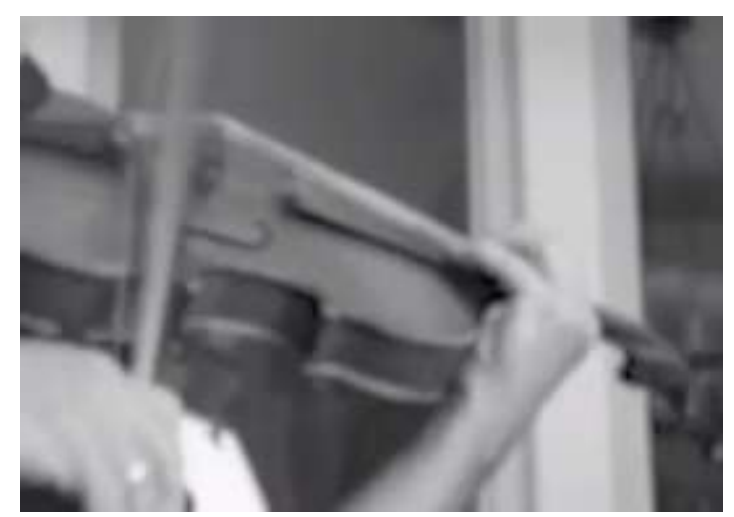

Gambar 1.

Cara menggesek string untuk mendapatkan timbre tertentu. 
Selain timbre, pengetahuan tentang ekspresi juga penting. Dalam musik, ekspresi diartikan sebagai ungkapan pikiran dan perasaan yang mencakup semua unsur musik. Di antaranya melodi, dinamik dan harmoni. Melodi merupakan rangkain bunyi musik yang di susun secara berurutan. Dalam film, melodi dapat digunakan sebagai pengungkapan rahasia perasaan. Rasa bahagia dan senang digambarkan dengan melodi yang ceria. Pemilihan intervalnya juga menggunakan konsonan.

Interval adalah jarak antar dua nada. Interval konsonan dapat diartikan sebagai pemilihan antar nada yang dapat di 'terima' oleh masyarakat luas. Lagu naik-naik ke puncak gunung misalnya. Begitu pula sebaliknya, rasa sedih atau takut diwakili oleh melodi yang lambat, melankolis, dan penggunaan interval disonan (pemilihan antar nada yang 'belum' dapat diterima oleh masyarakat luas).

Ekspresi dalam ilmu psikologi, dapat dikaitkan dengan emosi. Pola emosi antara satu orang dan yang lainnya memiliki karakteristik masing-masing dan berbeda. Perasaan senang, sedih, marah, takut seseorang dapat berubah. Proses perkembangan itu di dukung oleh beberapa faktor, baik internal maupun eksternal. Usia dan keluarga misalnya, adalah faktor internal. Sedangkan faktor eksternal seperti teman, musik, lingkungan dan sebagainya.

Hude (2006: 18) mendefinisikan emosi sebagai suatu gejala psiko fisiologis yang menimbulkan efek pada persepsi, sikap, tingkah laku, serta mengejawantah dalam bentuk ekspresi tertentu. Emosi dirasakan secara psikofisik karena berhubungan dengan jiwa dan fisik.

Psikolog mendefinisikan emosi pada tiga komponen perubahan fisiologis yaitu: wajah, otak, dan tubuh. Manusia pada dasarnya telah memiliki emosi primer semenjak mereka dilahirkan. Emosi primer meliputi rasa takut, marah, sedih, senang, terkejut, jijik, dan sebal. Emosi tersebut memiliki pola fisiologis dan ekspresi wajah yang berbeda. Kesedihan akan mengikuti persepsi kehilangan, rasa takut akan mengikuti persepsi ancaman atau disakiti, rasa marah akan mengikuti persepsi penghinaan atau ketidakadilan dan seterusnya. Sedangkan emosi sekunder meliputi semua variasi dan campuran berbagai emosi yang bervariasi antara satu dengan yang lain.

Secara fisik, ekspresi emosi manusia dalam melihat film dapat terlihat jelas pada raut wajah. Perhatikan saja ekspresi orang saat menonton film bergenre komedi atau horor. Tentunya scorenya harus mendukung. Perhatikan wajah 
audiens. Ekspresi tersebut pada musik di sebut efek gelap dan terang yang dihasilkan oleh harmoni musik.

Harmoni dapat diartikan sebagai suatu keselarasan antara komponen atau unsur yang ada dalam suatu jenis seni. Dalam arti yang spesifik, harmoni dalam musik adalah ilmu tentang akor ${ }^{2}$. Efek akor ini sangat mengagumkan, mempengaruhi warna pada score film. Umumnya, akor dapat diklasifikasikan menjadi tiga. Yaitu akor mayor, minor dan tujuh. Akor mayor dapat digunakan untuk membuat efek terang; efek gelap dapat menggunakan akor minor, sedangkan akor tujuh dapat digunakan untuk efek yang tidak selesai (mengambang). Tidak menutup kemungkinan komponis film bisa bereksperimen dengan menambahkan beberapa nada tambahan.

Perubahan efek tersebut, dari terang ke gelap menimbulkan perasaan seperti sedih, cemas, kasihan. Sedangkan akor mayor membebaskan kita dari perasaan gelap, akor mayor memberikan rasa tegar, gembira, optimis dan seterusnya.

Akor juga tidak bisa dilepaskan dari scale (tangganada). Pada tangganada mayor terdapat beberapa nuansa. Biasa di sebut dengan modes. Misalnya modes lidian, modes yang mempunyai nuansa ceria, mengambang, kesannya berada di ruang angkasa. Modes ini dapat dipilih sebagai pilihan utama dalam membuat score film yang bertemakan ruang angkasa. Belum dari scale-scale yang lain, eksotic scale misalnya. Hal ini bisa dipelajari lebih mendalam bagi para komponis film sebagai pengetahuan tambahan.

Melihat dua hal tersebut di atas yakni timbre dan ekspresi, score film bukanlah hal mudah. Juga tidak bisa dipersepsikan sederhana. Itulah kenapa seorang komponis musik film sangat di apresiasi. Sebut saja Hans Zimmer, Thomas Newman, John Williams dan yang lainnya.

Persepsi manusia berkaitan dengan indra pendengaran. Persepsi musik adalah bentuk khusus persepsi auditoris. Persepsi musik film membutuhkan pengenalan urutan-urutan not, aturan yang mengatur pitch, kombinasi harmonis akor dan not, serta struktur ritmis. Carlson (dalam Phetorant, 2018: 31) menjelaskan korteks auditoris kanan terlibat dalam persepsi irama yang mendasari musik,

\footnotetext{
${ }^{2}$ Awam menyebutnya dengan kunci.
} 
sementara korteks auditoris kiri tampaknya terlibat dalam persepsi pola pola ritmis yang bertumpuk dengan irama ritmis.

Film $A$ Il is Lost merupakan contoh yang menarik. Film tersebut disutradarai oleh J.C. Chondor yang di buat tahun 2013. Film yang hampir dapat dikatakan sebagai film bisu ini scorenya unik. Penulis mempersepsikan adanya score dengan menggunakan unsur atau elemen musik pada umumnya. Dari awal menonton, penulis menanti adanya unsur musik. Lima belas menit kemudian belum muncul juga. Karena masih penasaran, sampai akhir film tersebut, sangat sedikit sekali unsur musiknya. Kecuali pada bagian akhir. Score pada fim ini banyak menggunakan sound effect. Bahkan pada credit title-nya masih terdengar bunyi sound effect.

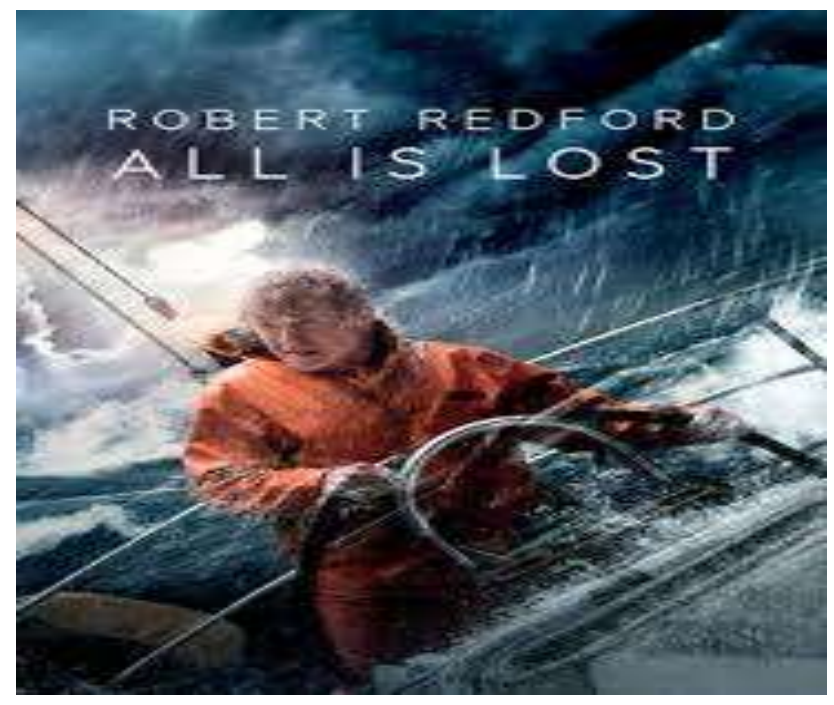

Gambar 2.

Film All Is Lost.

Hal tersebut bisa saja terjadi. Pada sebuah film di kenal adanya storyboard. Sebuah panduan bagi komponis untuk membuat musik ilustrasi. Umunya storyboard diberikan kata-kata atau dialog yang diambil dari naskah (scrip) yang diterjemahkan ke dalam gambar. Minimnya dialog bahkan hampir tidak ada itulah yang menyebabkan film ini banyak menggunakan sound effect atau SFX. Pembuatan score film tanpa dialog ini (All Is Lost), menjadi rasional jika sedikit menggunakan unsur musik pada umumnya. Selain itu, penempatan soundtrack film yang berdurasi selama kurang lebih satu setengah jam ini, juga kurang lazim. Karena diletakkan setelah credit title selesai. Terlepas dari ketidaklaziman tersebut, film ini meraih 
penghargaan 71 Golden Globe Awards dalam hal score asli terbaik. Asli di sini dikaitkan dengan sesuatu yang orisinal.

SFX pada film umumnya berasal dari ambience, foley, dan sound design. Ambience berkaitan dengan kesan ruang. Pengambilan gambar pada sebuah ruang/gedung tertutup berbeda dengan pengambilan set gambar pada ruang terbuka. Suara kendaraan, atau penonton dapat memberikan kesan ruang. Semua itu dilakukan untuk memperjelas visual. Foley merupakan reproduksi efek suara yang disinkronisasi pada suatu film. Foley membantu sebuah adegan menjadi lebih realistis. Sound design dapat diartikan membuat efek suara yang tidak alami. Seperti suara kuda yang dihasilkan dari suara gitar elektrik dimainkan dengan teknik whammy bar'.

Satu hal lain yang sering dilupakan para pembuat score adalah mengetahui sejarah musik. Jauh sebelum score musik seperti sekarang, musik sudah melewati beberapa periodenya. Dari abad pertengahan, zaman renaisans sampai dengan musik abad ke-20. Belum dilihat dari keunikan motif atau corak para komponis.

Beethoven dapat dikatakan sebagai komponis awal pembuat motif musik yang kuat. Beethoven hidup dalam dua periode musik, klasik dan romantik. Simfoni no. 5 contohnya. Motifnya berdasarkan irama not seperdelapan dan setengah yang kuat. Jika diucapkan iramanya ta-ta-ta-ta.

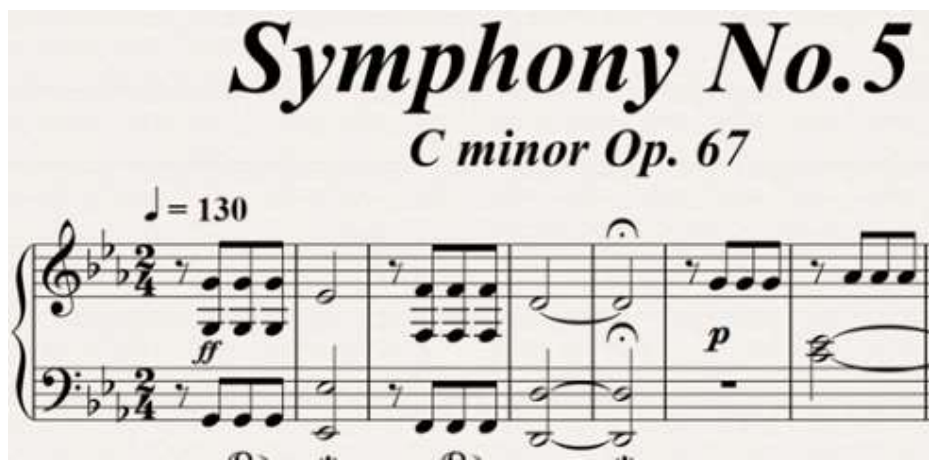

Gambar 3.

Notasi Simfoni no. 5 Beethoven

Lain lagi dengan Berlioz. Komponis romantik yang ahli orkestrasi. Salah satu disiplin ilmu musik untuk orkestra. Sebagai contoh: klarinet dapat digunakan sebagai

\footnotetext{
${ }^{3}$ Suatu teknik gitar elektrik dengan memainkan handle gitar. Tujuannya untuk mendapatkan efek bunyi tertentu.
} 
alternativ pengganti saxophone alto. Untuk membuat suara gelap dan suram dapat menggunakan tiga saxophone dan satu bariton. Atau French horn yang dipadukan dengan klarinet dan saxophone dapat menghasilkan atmosfer chamber grup dsb. Motif musik Berlioz dapat ditemukan dalam simfoni Fantastique-nya. Di sebut juga dengan idée fixe. Suatu motif musik muncul berulang-ulang secara terus menerus. Menandakan atau menggambarkan kemunculan suatu tokoh atau kejadian tertentu. Motif tersebut membantu penonton untuk mengerti keterkaitan hubungan dalam cerita film.

Perkembangan lebih lanjut dari idée fixe ini berada pada akhir era romantik. Namanya berubah menjadi leitmotiv. Sebuah kalimat musik pendek yang menerangkan ide, objek tertentu, baik itu terlihat atau pun tidak, yang dipersepsikan sedemikian rupa oleh audiens. Leitmotiv bertugas untuk menerangkan, menarasikan, atau memberikan pemahaman terhadap hubungan antar bagian di dalam suatu permasalahan. Dengan demikian, motif musik dihasilkan dari keterkaitan gambar secara utuh. Leitmotif berkaitan dengan musik film. Contoh leitmotiv terdapat pada karya komponis Wagner yang berjudul Tristan und Isolde.

Abad ke-20, film Entracte di sebut sebagai contoh musik film. Film yang disutradarai oleh Rene Clair ini, score nya di buat oleh Eric Satie. Seorang komponis yang dikaitkan dengan istilah kubisme. Bahkan John Cage menyebut Satie sebagai pelopor. Entr'acte adalah karya yang berkesinambungan, berdurasi sekitar dua puluh menit, dan scorenya menggunakan orkestra kecil. Score Satie, banyak diklaim memberikan nilai dan fungsi baru untuk musik film.

Selama belasan tahun terakhir dari periode hening (dari sekitar tahun 1915 dan seterusnya), sebagian besar film adalah produk industri yang ceritanya ditujukan untuk menghibur penonton. Satie membuar score dengan sikap Wagner (leitmotiv), dari pola berulang yang mengambang. Dalam Bahasa teknisnya, tidak kembali ke tonika. Satie menyebutnya dengan musique d'ameublement/ furniture music. Satie menggunakan istilah ini untuk menggambarkan musik fungsional, sebuah musik untuk sarana hiburan. Saat itu, musik latar film dan musik furnitur dianggap tidak berbeda. Musik film di anggap sebagai respons terhadap kebutuhan dasar (untuk menutupi masalah kebisingan). Musik Satie tidak menafsirkan gambar Entracte. Secara keseluruhan score yang dibuat Satie menyatu dengan gambar, mendukung 
film, membantu memperjelas struktur dan memperluas jangkauan makna film Entr'acte.

Selain musik serius, dalam musik populer juga banyak ditemukan musik latar film. Jazz misalnya. Di amerika, jazz adalah musik populer. Sedangkan di Indonesia, jazz bukan merupakan musik populer. Jazz sebagai musik latar film terdapat dalam film: Walk on the Wild Side - Elmer Bernstein, 1965; The Pink Panther - Henry Mancini, 1964, dan sebagainya. Dengan mengetahui sejarah perkembangan musik, para komponis film dapat menambah dan menggali perbendaharaan referensi musiknya.

Suatu film apabila didukung dengan score yang baik, penonton makin menikmati film dengan lebih nyaman dan tanpa memiliki perasaan canggung tentang film yang mereka saksikan.

\section{SIMPULAN}

Score tidak hanya sebatas membuat musik. Score juga bukan pengganti pesan dari satu gambar ke notasi musik atau bunyi. Proses pembuatan score pada film membutuhkan imajinasi dan wawasan yang luas. $\mathrm{Di}$ antaranya adalah menguasai unsur musik, seperti timbre, interval, dan Mengetahui perkembangan sejarah musik barat tentu dapat menambah nilai lebih bagi komponis film.

Unsur psikologi juga harus diperhatikan oleh komponis film. Misalnya bagaimana membuat interval nada, atau pemilihan akor yang dapat menimbulkan emosi sedih, gembira pada audiens. Pemilihan nada yang tepat dapat membuat audiens lebih nyaman dalam menyaksikan film-film.

Musik film merupakan salah satu genre penting di abad ke-20. Dengan musik score kita bisa melihat komponis membawa masuk gambar ke dalam musik dengan intuisinya. Kombinasi hubungan timbal balik ini (gambar dan musik) sangat unik. Inilah yang membuat score menjadi kuat dan misterius.

Sayangnya, musik film belum mendapatkan perhatian yang serius dari lembaga pendidikan di Indonesia.

\section{REFERENSI}

Hude, Darwis M. 2006. Penjelajahan Religio Psikologis tentang Emosi Manusia dalam Al-Quran. Jakarta: Erlangga 
London, Kurt. 1970. Film Music (The Literature of Cinema Series). New York: Arno Press.

Manvell, Roger and John Huntley. The Technique of Film Music. Jakarta: Proyek Penterjemahan Yayasan Citra.

Phetorant, Dimas. 2018. Psikologi dan Musik. Jakarta: CV. Nada Group. 